\title{
O USO DA VENTOSATERAPIA E SUA ATUAÇÃO NA ESTÉTICA
}

\author{
THE USE OF SUCTION THERAPY AND ITS PERFORMANCE IN AESTHETICS
}

\begin{abstract}
Andrea Paula Araujo ${ }^{1}$
Iolene de Sousa ${ }^{2}$

RESUMO: Este estudo visa descrever os diversos usos da ventosaterapia especialmente na área da estética. Tal procedimento consiste na desobstrução de qualquer tipo de inativação do corpo, movimentação do sangue, assim como na renovação do vigor. Deste modo, é uma metodologia medicinal oriental com vários anos de sucesso e permeada de evidenciação que contribui grandemente para a saúde do ser humano. Por este motivo tem sido empregada na área da estética de forma recorrente, como apresentado ao longo deste trabalho. A presente pesquisa serve-se de uma revisão teórica para a coleta de dados, a qual utiliza fontes terciárias tais como: livros, trabalhos acadêmicos, sites, entre outras, publicadas entre 2015 e 2021. Os resultados apontam que este tipo de método tem sido bastante explorado devido a sua eficiência a um custo baixo. Sendo assim, relatos presentes na literatura mostram a sua eficácia na cicatrização, amenização das estrias, redução da circunferência abdominal, drenagem linfática, redução das celulites e redução da retenção de líquidos pelo organismo.
\end{abstract}

Palavras-Chave: Estética. Procedimento. Ventosaterapia.

\section{INTRODUÇÃO}

O uso da Ventosaterapia como técnica de tratamento de anomalias, existe há milênios, e seu poder terapêutico atravessou várias civilizações. Deste modo, foi muito utilizada pela medicina tradicional chinesa. Assim, é uma prática que se espalha ao redor do mundo que trabalha o relaxamento mental e corporal das pessoas.

De acordo com Amaro at al. (2015), este procedimento consiste em provocar um vácuo para fazer a sucção da pele, ocasionando um vácuo que estimula a circulação sanguínea, assim como libera as toxinas do sangue. Além disso, esta técnica atua na limpeza do sangue, o que aumenta a sua resistência a doenças, assim como uma melhor oxigenação da pele. Enfim, a ventosa drena áreas congestionadas e libera as energias negativas do corpo.

Por conseguinte, esta técnica tem vários métodos de aplicação, podendo ser alternada com outras técnicas presentes na medicina chinesa tradicional. Desta maneira,

\footnotetext{
${ }^{1}$ Graduada pelo Instituto Tocantinense Presidente Antônio Carlos. (UNITPAC) Campus Araguaína-TO em farmácia. Pós graduada em Estética pelo IEES- Instituto de Excelência em Educação e Saúde.

${ }^{2}$ Graduada pelo Instituto Tocantinense Presidente Antônio Carlos (UNITPAC) Campus Araguaína-TO em Enfermagem. Pós graduada em Estética pelo IEES- Instituto de Excelência em Educação e Saúde.
} 
esta alternativa terapêutica é indicada no tratamento de algumas anomalias, atuando em distúrbios reumatológicos, neurológicos, vasculares e dermatológicos, assim como em tratamentos estéticos. Enfim, os fisioterapeutas utilizam muito este método para o tratamento de patologias crônicas e em tratamentos de dor aguda dos pacientes.

De acordo com Amaro at al. (2015), este procedimento consiste em provocar um vácuo para fazer a sucção da pele, ocasionando um vácuo que estimula a circulação sanguínea, assim como libera as toxinas do sangue. Além disso, esta técnica atua na limpeza do sangue, o que aumenta a sua resistência a doenças, assim como uma melhor oxigenação da pele. Enfim, a ventosa drena áreas congestionadas e libera as energias negativas do corpo.

Nas considerações de Fornazieri (2013), a aplicação das ventosas auxilia no tratamento da lipodistrofia, dessa forma motiva o organismo a excluir resíduos metabólicos e liberar toxinas residuais. Além disso, a gordura localizada é reduzida, deixando apenas nos lugares onde tem função orgânica. Assim, no caso da celulite, usa-se o método deslizante e de sucção média a leve. Deste modo, estimula o sangue e o metabolismo lipídico. Finalmente, no rosto, age tratamento de rugas, aumentando a produção de colágeno e elastina, assim como drenagem linfática e contorno facial.

Deste modo, esta pesquisa se orienta através de questões norteadores sobre esta problemática, tais como: De onde surgiu a técnica de ventosaterapia? Em que consiste este tratamento? Quais são os benefícios reais no tratamento de procedimentos estéticos? Quais são as contraindicações para esta técnica? Quem é o profissional capacitado para a realização de tal procedimento? Quais são os casos que podem ser tratados através deste método?

Por conseguinte, para fazer esta pesquisa foi utiliza uma revisão teórica, com uma busca por termos descritores tais como: Ventosaterapia, Tratamentos estéticos, Medicina Tradicional Chinesa, entre outros. Deste modo, foram consultadas plataformas de fontres científicas, tais como: Capes e Scientific Electronic Library Online - SCIELO, Google Acadêmico, revistas cientificas, etc. para fundamentar este artigo. Deste modo, trata-se de um estudo exploratório-descritivo, onde o foco é analisar dados para produzir conhecimento. 


\section{BREVE HISTÓRICO DO USO DA VENTOSATERAPIA EM TRATAMENTOS}

Nos tempos contemporâneos, a estética é um ramo em grande expansão, ganhando milhares de adeptos aos tratamentos estéticos. Por conseguinte, este trabalho apresenta uma técnica chamada ventosaterapia, que tem mostrado resultados positivos em relação tratamentos estéticos. Assim, como a satisfação dos usuários, a procura por este tipo tratamento aumentou, o que exige estudos científicos sérios, para poder mostrar as vantagens que o seu uso propicia.

Nas considerações de Al-Bedah (2019), devido ser bastante utilizada para várias finalidades, a ventosaterapia está associada a vários procedimentos. Exemplo disso é o uso como terapêutica para o controle da acne vulgar, onde o seu desaparecimento é notado em pouco tempo. Ademais, a sua eficácia no controle da obesidade é notável. Segundo este autor, resultados em estudos recentes mostram que este tratamento melhora a circulação sanguínea, aumentando assim a oxigenação do sangue, deixando o corpo mais saudável e disposto a praticar exercícios físicos.

De acordo com Cardoso (2018), este tipo de procedimento é bastante antigo, sempre amplamente difundida nos países do oriente, especialmente na China. Deste modo, a sua utilização está relacionada especialmente a desobstrução de vias corpóreas, onde promove a renovação das células. Assim, por ser um método comprovado pela ciência, é confiável para ser utilizado com humanos. Por este motivo é objeto de estudo deste trabalho de conclusão de curso, por ser de grande relevância para a sociedade e para a ciência.

Segundo Coelho (2019), não se têm a data precisa de quando se iniciou a prática da ventosaterapia. Porém segundo relatos esta metodologia iniciou ainda no Egito. Neste sentido, evidências foram encontradas em manuscritos de Hipócrates no século IV A. C., os quais comprovam que antigos curandeiros utilizavam a ventosa com a finalidade de serem usados no tratamento de patologias em seres humanos.

Nas teorias de Filho (2017), os chineses utilizavam as ventosaterapia com chifres de animais, fazendo assim tratamentos mais intensos em pacientes acometidos por doenças infeciosas. Com isto, vários tipos de ventosas eram misturados a um pó branco, obtido a partir da serragem de chifre acumulado em potes de plástico. Então, a amplitude de doenças tratadas foi maior, o que ocasionou a popularidade do seu uso. 
Calogero (2017) menciona que após o término do procedimento comumente o local aonde eram colocadas as ventosas sofre uma nova coloração visilvemente diferenciada na pele ao seu entorno, podendo assim surgir manchas com tonalidades diferenciadas, sendo por vezes tais coloraçõesutilizadas como parâmetro para a análise da terapêutica realizado pelo profissional.

Nos estudos de Forter et al. (2018), os vários tipos de colorações sempre se nota quando foram aplicadas as ventosas em determinada região com alguma lesão a pele, a qual ficava roxa com tons de hematomas em. Ademais, alguns casos até mesmo tiveram manchas escuras, assim como marcas avermelhadas. Contudo, quando este método é aplicado corretamente é um excelente tratamento. Deste modo, Filho (20r6), aconselha que é de suma importância realizar a quantidade correta absorvência, adequando-se à necessidade do paciente, com um procedimento que gere satisfação e bem-estar.

A esse respeito, Oliveira (2018) manifesta que esse procedimento têm sido empregado especialmente devido seus diversos efeitos, tanto no âmbito terapêutico, quanto na area do esteticismo que consiste na sucção através uma bomba absorção de ar mecânica. Pereira (2017) também adverte que só se deve colocar ventosa uma vez, alternando a sucção em várias partes. Fazendo assim, serão realizadas ligeiras sucções, aplicando produtos oleosos, que permitem melhores movimentos direcionados a circulação corporéa.

Além do mais, Reis (2018) salienta que o permanecimento das ventosas em um determinado local do corpo, deve ocorrer até o surgimento da zona local. Em oposição à permanência que pode resultar no aparecimentode hematomas, peculiarmente índividuos com fragilidade capilar.

Melhor dizendo, esteticamente a técnica das ventosas consiste em reslavos no tecido proporcionando uma fricção de vácuo. Assim fazendo, aumenta a oxigenação do sangue, promovendo a aceleração do metabolismo, tendo como consequência, maior circulação do linfá no sangue. Além disso, Oliveira (2019) ainda afirma que a metodologia quanto aplicação do procedimento pode ser realizado de duas formas, sendo estas: a aplicação de forma inerte e o uso de óleos, dependendo de cada caso.

De acordo com Coelho (2019), durante muito tempo empregam-se estes dois métodos com uso das ventosas, sendo uma seca e uma molhada. Deste modo, eram 
recomendadas irritações, dor, assim como incómodos na musculatura. Assim, a ventosa seca esta era aplicada principalmente na pele sem nenhum tipo de hidratante, gerando rutura da epiderme. Em contrapartida, na metodologia denominada de ventosa molhada, o tecido sofria a lesão através do uso lâminas cortantes, gerando um sangramento antes da aplicação da ventosa seca.

Neste sentido, Gouveia, Nunes, Pereira e Assis (2018) falam o seu uso estético. Deste modo, o procedimento age principalmente na extração dos glânglios de gordura presentes no corpo, que são causadores das conhecidas celulites. Assim, o tratamento interfere diretamente no movimento correto do sangue, na extração do colesterol, estimulando o corpo a realizar a separação dos resíduos metabólicos das toxinas residuais.

Nas teorias de Fornazieri (2005), especifica-se que tal terapia possui ação anti rugas, amenizando os sinais de expressão facial. Neste sentido, é responsável pela produção de colágeno e da elastina, levando a oxigenação das células, a massagem linfática e grandes melhorias no contorno facial. Além disso, de acordo com Cardoso (2018), este procedimento é bastante empregado tanto na estética como na fisioterapia especialmente quando o paciente apresenta alguma forma de lesão facial em pacientes acometidos por Acidente Vascular Cerebral (AVC).

Nas considerações de Oliveira et al. (2018), o sucesso deste tratamento deve-se ao fato de ter poucas contraindicações, e poder ser utilizado em pacientes dos mais variados perfis. Com isso, o seu uso se intensificou junto com outros procedimentos como tratamento capilar em homens e mulheres, os quais podem melhorar o nascimento dos cabelos no couro cabeludo. Diante disto, este tratamento promete ter um diferencial significativo, quando comparado com outros tratamentos mais invasivos e desconfortáveis.

\section{MATERIAL E MÉTODOS}

Para a realização deste artigo utilizou-se como método de coleta de dados, um procedimento de revisão teórica, em plataformas de busca da internet, tais como Scielo, Google Acadêmico, Revistas científicas, entre outras. Desta forma, foram realizadas as leituras, fazendo o devido resumo de cada uma dela, assim como retirando as citações 
através de estratégias de fichas. Assim, foram usadas palavras-chave, tais como: estética, procedimento, ventosaterapia, entre outras.

Deste modo, foram consultadas 356 publicações nas bases de dados sobre estes assuntos. Em seguida foram selecionados is artigos seguindo o critério de inclusão e exclusão. Assim, io artigos foram encontrados na base de dados da Scielo e 5 no Google Acadêmico. Por conseguinte, a pesquisa ocorreu entre os meses de Março de 2021 e Junho de 202I, incluindo assim a coleta de dados e posteriomente a análise dos materiais científicos do tema abordado.

Além disso, foram considerados os artigos publicados no período de 2015 a 2021, assim com o conteúdo relacionando Ventosaterapia a tratamentos estéticos. Em contrapartida, foram excluídos todos os textos repetidos e aqueles que não abordava em nenhum quesito os objetivos da pesquisa como na Figura or.

Figura r. Desenho metodologico de busca dos dados

\section{O uso da ventosaterapia e sua atuação na estética}

Descritores: Ventosaterapia, estética e bem-estar.

Scielo: 250 publicações;

Google Acadêmico: 106 publicações

Scielo: $250 \quad$ publicações

\section{Exclusão:}

- Fora do período estabelecido entre 2015 e 2021: 110 publicações;

- Não traziam o texto na integra: 110 publicações;

-Textos repetidos: 50 publicações;

- Não contemplaram os objetivos: 30 publicações;

- Amostra: 10 publicações.
Google Acadêmico: 106 Publicações

Exclusão:

- Fora do período estabelecido entre 2015 e 2021: 45 publicações;

- Não traziam o texto na integra: 15 publicações;

-Textos repetidos: 35 publicações;

- Não contemplaram os objetivos: 6 publicações;

- Amostra: 5 vublicacões

Amostra final: 15 artigos

Fonte: o uso da ventosaterapia e sua atuação na estética 
Para que pudéssemos examinar o material pesquisado, inicialmente foi realizada uma leitura bastante rigorosa dos textos e, em seguida, a análise do conteúdo presente em cada um deles, de modo que se permitisse responder comovidamente as perguntas norteadores e objetivo do estudo em questão.

\section{RESULTADO E DISCURSÃO}

A prática da ventosaterapia é milenar, sendo difundida principalmente nos países asiáticos. Para a realização desse método por muito tempo foram utilizados equipamentos feitos utilizando os chifres de animais como podemos observar na (Figura I). Deste modo, Conrradi (2019) afirma que os chifres recebiam todo um preparo para seu uso, desde do corte que devia ser entre $10-15 \mathrm{~cm}$ de comprimento, até o diâmetro interno que deveria se de $5 \mathrm{~cm}$. Além disso, na parte externa era realizado um acabamento bem delicado para não machucar o paciente durante a realização do procedimento.

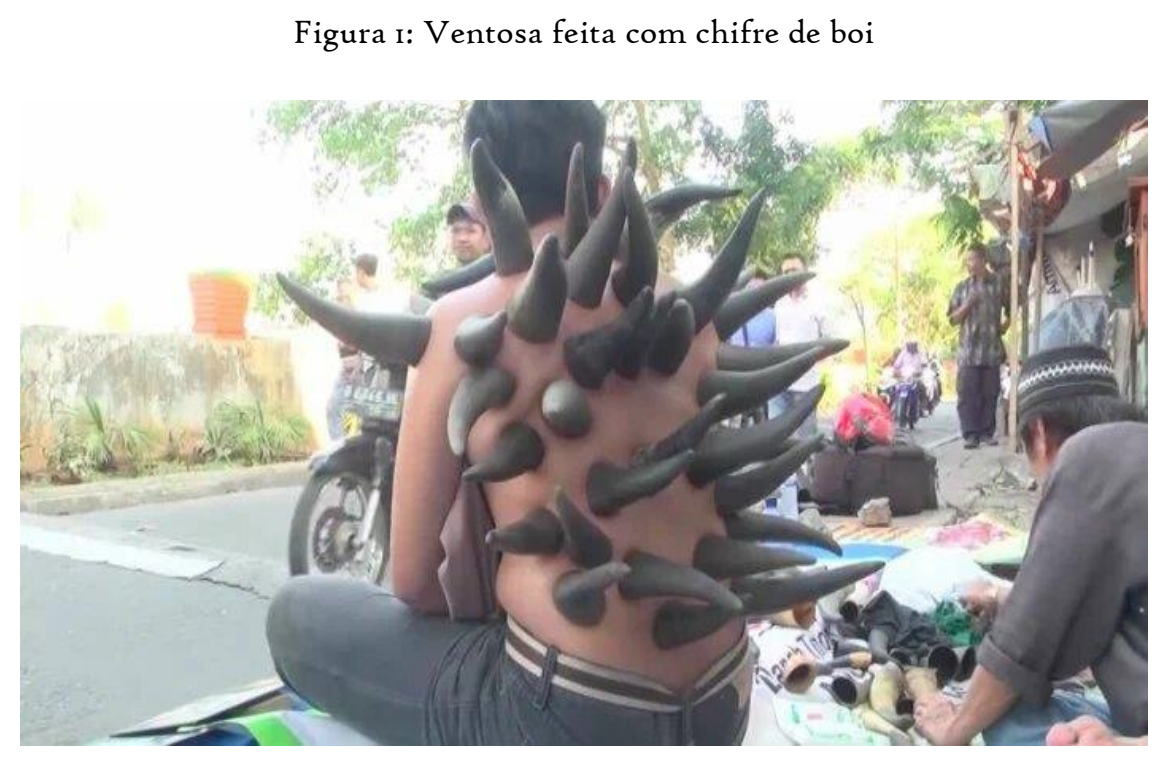

Fonte: google pictures

Outros modelos de ventosas utilizavam bambu para fazer os utensilios, por isso, no oriente principalmente, os chineses cultivavam o bambu apenas para este fim. A este respeito, Coelho (2019) descreve que medida era de 6 a $9 \mathrm{~cm}$ de cumprimento, com o, $6 \mathrm{~cm}$ de diámetro, sendo que a parede desse instrumento era de apenas I cm. Além do mais, era 
realizado um acabamento especial externo e interno para a prevenção de feridas e lesões. Enfim, o seu emprego foi intensificado por causa do seu baixo custo e resultados incríveis. Em contrapartida, o profissional apresenta grande dificuldade em realizar a higienização do instrumento, devido à sua aspereza constatada na Figura 2.

Figura 2: Ventosa de Bambu

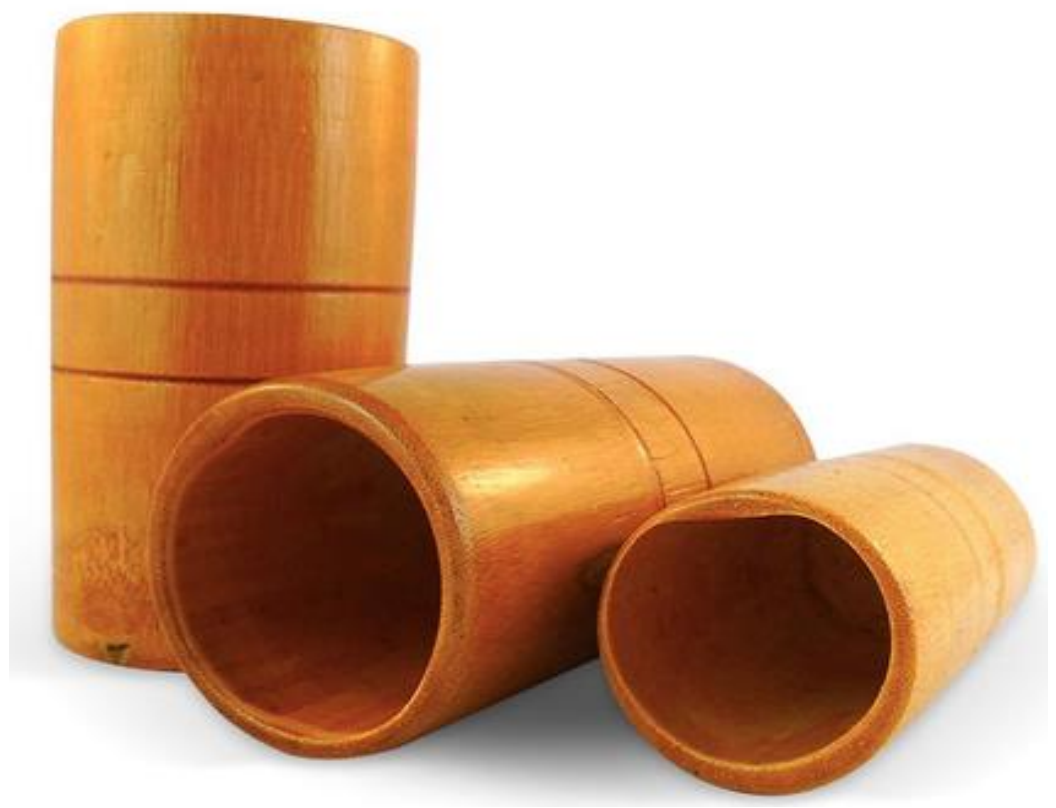

Fonte: https://www.institutohishinuma.com.br/o-que-e-ventosaterapia/.

Mello (2016) aponta outro modelo que também é bastante usado na atualidade, é uma ventosa fabricada a partir de caucho, o qual tem uma ondulação característica. Desta maneira, a sua surção é tão forte, quepode ser utilizada por cima da roupa, o que evita constrangimentos. Por isso, são instrumentos de uso clínico em um público mais sensivel, como crianças e idosos, sem colocar a saúde em risco.

Entretanto, Hongo (2020) observa que estes instrumentos têm algumas desvantagens em relação aos outros. Entre estas podem-se destacar que, devido sua estrutura o profissional não consegue visualizar a estimulação, o que acaba atrapalhando a realização da sucção. Além disso, não é visível a presença de hiperemia aonde está sendo aplicado a ventosa, impedindo a análise do sangue durante a realização das sangrias. 
Figura 3: Ventosa de Borracha
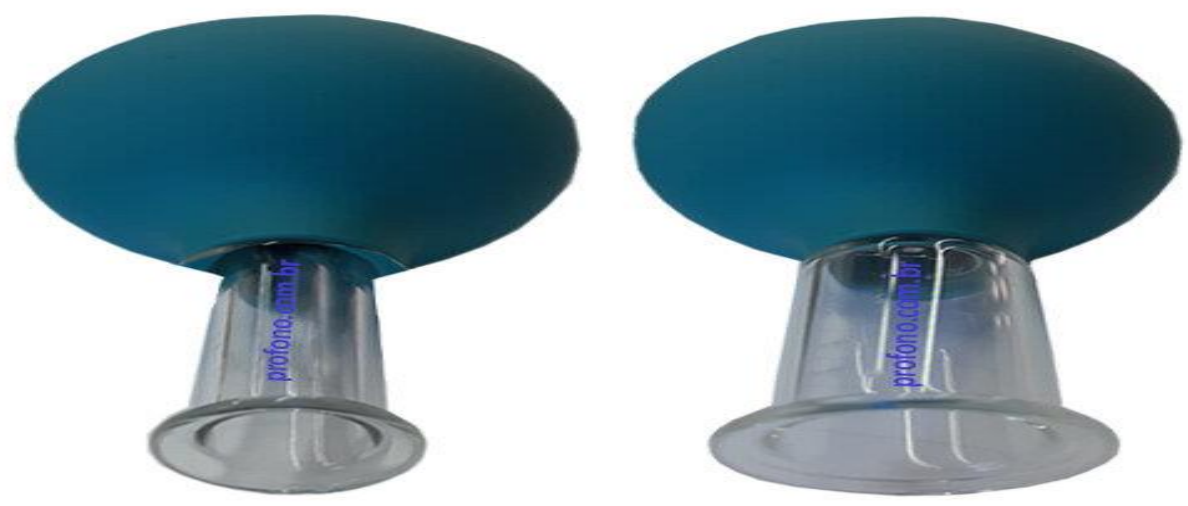

Fonte: https://profono.com.br/loja/ventosas-orofaciais-pro-fono/

De acordo com Pires (2018), outra ventosa bastante utilizada dentro dessa área, são as ventosas em forma de cilindro de acrilico, por causa da sua resistência e translucidez. Além disso, apresenta uma válvula na parte superior desse instrumento. Deste modo, este dispositivo é acionado por uma bomba manual, encaixando a ventosa e controlando por meio da válvula. Assim fazendo, uma sucção que não machuca a pele, sendo ajustada para cada caso individualmente.

Por conseguinte, o uso por esteticista está relacionado ao baixo custo, além de ser de fácil higienização devido sua estrutura ser de material acrílico, de fácil manuseio por translúcido, apresentando vários tamanhos e formatos.

Figura 4: Ventosa de Acrílico

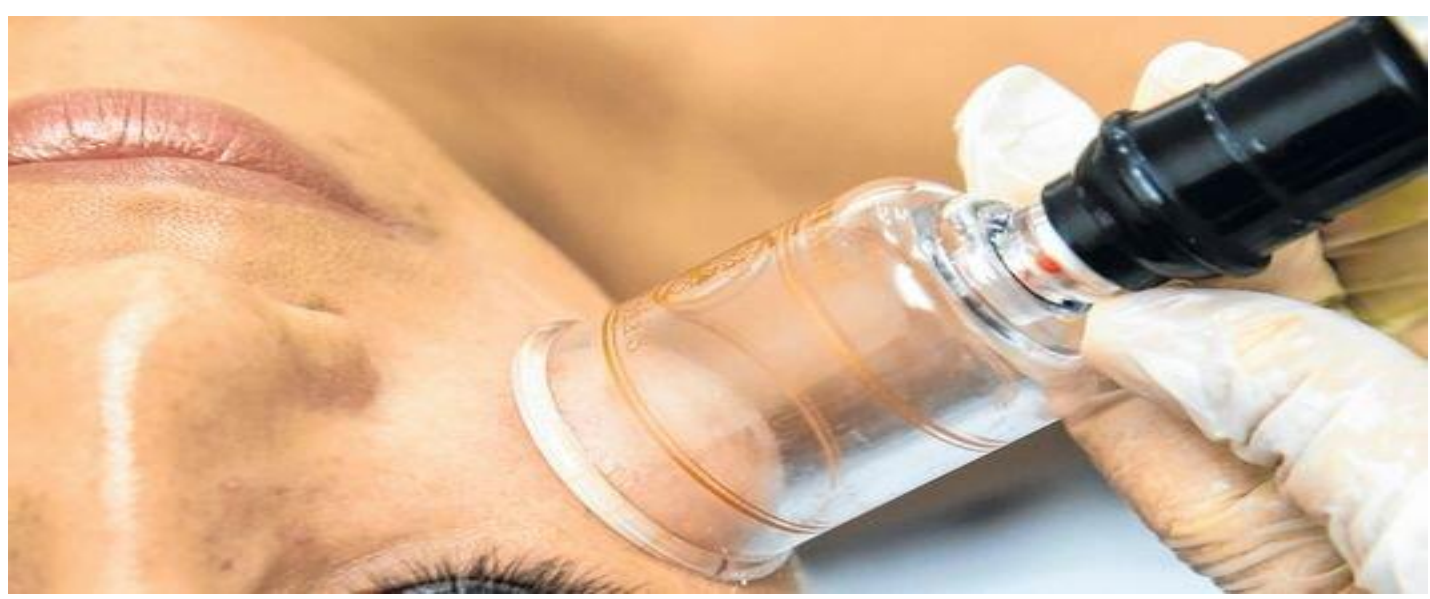

Fonte:https://diariodonordeste.verdesmares.com.br/verso/terapia-facial-com-ventosa-I.2137634 
Nos estudos de Volpato (2017), não importa o material com o qual a ventosa é fabricada, o importante é ela cumprir a sua função sem causar grandes danos. Desta forma, serão benefiadas cada vez mais pessoas, por poder atender pacientes desde a infância, até a terceira idade. Assim, com a amplitude deste público usuário, é necessário que as pesquisas científicas acompanhem esta evolução, para ter mais dados sobre o seu uso.

A força realizada pelo vácuo é controlada pelo esteticista que pode ser baixa, média e forte, dependerá da finalidade, a intensidade será controlada pelo esteticista, que detém o conhecimento do que objetiva-se com a realização do procedimento. A aplicação é realizada utilizando-se uma máquina está realizando comando pressão do ar que será retirado totalmente do instrumento (FILHO, 2016). No quadro I temos descrito como é utilizada essa bomba durante a ventosaterapia. No quadro i temos descritocomo é utilizada essa bomba durante a ventosaterapia .

Quadror : Regulagem da Bomba de vasoterapia conforme o vácuo desejado

\begin{tabular}{|c|c|}
\hline Doseamento & Bomba \\
\hline Fraco & Puxa-se a bomba apenas I vez \\
\hline Moderado & Puxa-se a bomba 2 vezes \\
\hline Forte & Puxa-se a bomba de 3 a 4 vezes \\
\hline
\end{tabular}

Fonte: Livro Ventosaterapia Teoria e Prática

Os estudos de Filho (2016) apresentam que cada dosagem de vácuo empregada pelo esteticista na pele do paciente realiza uma pressão no tecido. Neste seguimento, a utilização do vácuo é conforme a finalidade almejada no procedimento. Além disso, quando a sucção é fraca, de entre 2 ou $3 \mathrm{~mm}$, o paciente não sente dor e nem desconforto no local da ventosaterapia. Com isso, o sangue fica mais agitado, promovendo uma oxigenação integral nos tecidos menos expostos.

Por outro lado, Coelho (2019) assevera que a ventosaterapia de intesidade média promove a tonificação da pele, uma vez que sofre a aspiração sem extrapolar os $5 \mathrm{~mm}$ de pressão. Deste modo, a sucção ocorre de forma moderada, não causando nenhum tipo de 
desconforto e aumentando a circulação sanguínea com a liberação de fluídos.

Em contrapartida, Filho (2016) apresenta que a ventosoterpaia com uma forte sucção é utilizada para produzir pressão negativa, ficando em torno de $8 \mathrm{~mm}$. Desta maneira, isto pode causar incômodo, assim como a irritabilidade do local, causando manchas intensas nos locais aplicados que desaparecem em alguns dias. É importante ressaltar que a aplicação de ventosa nessa intensidade não pode ser realizada na face, apenas no corpo.

Finalmente, Filho (2016) afirma que o emprego mais comúm desta sucção forte é para tonificar os músculos. Este fortalecimento depende do perfil do paciente, quando se trata de pessoas que praticam exercícios de alta performance, isto pode acontecer. Deste jeito. pode ser aplicada de forma firme, melhorando dessa forma o vigor. Por conseguinte, o robustecimento é garantido, como demostrado no quadro 2, se recomendam os estímulos que podem ser realizados durante cada aplicação.

Quadro 2: recomendações dos estímulos na Ventosaterapia

\begin{tabular}{|c|r|r|r|}
\hline Método & Dosagem mínima & Dosagem média & Dosagem alta \\
\hline $\begin{array}{c}\text { Fogo } \\
(40 \mathrm{~cm} / \mathrm{Hg})\end{array}$ & 5 segundos & 20 segundos & 40 segundos \\
\hline $\begin{array}{c}\mathrm{Manual}(50 \mathrm{~cm} \\
/ \mathrm{Hg})\end{array}$ & 5 segundos & 20 segundos & 40 segundos \\
\hline $\begin{array}{c}\text { Elétrica }(60 \mathrm{~cm} \\
/ \mathrm{Hg})\end{array}$ & 3 segundos & 10 segundos & 20 segundos \\
\hline
\end{tabular}

Fonte: FILHO, 2016)

Nas teorias de Boushanab (2018), por causa da grande força de absorção, aonde o estabelecimento do vigor e sangue é maior no local aonde se coloca a ventosa, faz com que aconteça a propagação e liberação das estagnações. Por outro lado, em relação a potência de dispersão, ocorre uma mudança na cor da pele, se tornando da cor vermelha e posteriormente se modifica para roxa.

Filho (2016) mostra nas suas pesquisas que na primeira aplicação geralmente a metodologia é bastante acentuada, causando as manchas de equimoses, as quais ficam presentes nos locais aonde fora aplicado a ventosa. Porém, depois de 14 dias estas 
desaparecem totalmente. Por isso, no começo de cada procedimento a ventosa é utilizada de forma leve, aumentando a sucção gradativamente conforme as sessões vão passando, conforme se pode observar no quadro 3 .

Quadro 3: Apresentação da metodologia em uso na ventosoterapia

\begin{tabular}{|c|c|c|c|}
\hline Materiais & $\begin{array}{c}\text { Dosagem } \\
\text { mínima }\end{array}$ & $\begin{array}{c}\text { Dosagem } \\
\text { média }\end{array}$ & Dosagem alta \\
\hline $\begin{array}{c}\text { Fogo } \\
(40 \mathrm{~cm} / \mathrm{Hg})\end{array}$ & I minuto & 2 minutos & 3 minutos \\
\hline $\begin{array}{c}\mathrm{Manual} \\
(50 \mathrm{~cm} / \mathrm{Hg})\end{array}$ & I minuto & 2 minutos & 3 minutos \\
\hline
\end{tabular}

Fonte : FILHO, 2016.

A este respeito, Borges (2016) diz que um método explorado em sua grande pontecialidade dentro dos centros estéticos é a ventosa deslizante que apresenta como principal intuito o de ser administrado em determinadas áreas que passaram pela terapêutica. Neste seguimento, inicialmente a área deve ser lubrificada com creme ou óleos corporais. Deste modo, os copos das ventosas irão se fixar melhor, promovendo dessa forma o método deslizante, essencial para os esteticistas que utilizam a ventosaterapia como alternativa de tratamento.

Nesse momento, Nasb (2020) assevera que o esteticista utiliza a ventosa com movimentos realizando rapidamente em equilíbrio com a pele, direcionado a sucção direcionando de cima para baixo, da esquerda para a direta, repetindo essa prática várias vezes. Assim, essa prática contribui para a redução da celulite, modelagem do corpo, entre tantos outros procedimentos utilizando esse método. Por conseguinte, dependendo potência da sucção empregado na ventosaterapia, sua atuação chega a várias estruturas, tais como os tecidos: cutâneo, subcutâneo e músculos. Com essa prática obtêm no corpo após a realização do procedimento, com a ablução sanguínea e realização de estímulo da circulação e das fibras musculares e estímulo mais rápido.

Segundo Moura (2019), a ventosaterapia tem grande potencial, pois é empregada em várias áreas como a fisioterapia. Desta maneira, é destinada para o controle das dores crônicas, no entanto, até o presente momento não se tem informações contundentes que 
explicam o processo como contribuinte para a diminuição das dores. Contudo, acredita-se que este efeito está relacionado à teoria comportamental do organismo. Além disso, está a ação do sistema imunológico e do processo de desintoxicação corpórea que esta terapia fornece, segundo a literatura atualizada.

O procedimento é conhecido mundialmente, onde alguns especialistas indicaram o uso deste procedimento, como método terapêutico, sendo utilizado para tratamento de insônia. Ademais, a ventosaterapia promove melhorias na qualidade do sono, melhorando também a ansiedade. Enfim, esta técnica é a responsável por proporcionar um relaxamento corporal e mental em pacientes submetidos a esta técnica.

Nos registros de Al-Bedah (2019) consta que esta terapia está associada à perca de peso. Deste modo, reduz a ansiedade, a qual é a principal causa da obesidae, por causa desta dar vontade de comer. Então, uma pessoa magra é capaz de engordar e uma pessoa acima do peso é capaz de reduzir as suas formas. Além disso, pode ser usada também como regulador da obesidade, ficando nem gorda nem magra. Conclui-se, então que esta técnica é eficiente para um mal que ataca a humanidade, desde o período neolítico.

Neste sentido, Al-Bedah (2019) também afirma que o esteticista assim como demais médicos devem orientar os pacientes sobre os benefícios dessa metodologia. Assim, deve ser ressaltado que o procedimento só deve ser realizado por um profissional competente para evitar riscos devido a prática mal realizada. Nesta ótica, Toffanello (2017) procurou utilizar esta técnica para a redução do abdómem comprovadas em cinco mulheres de idades entre vinte e trinta anos de idade. Com isto se notou uma redução na circunferência abdominal destas mulheres, deixando os maridos mais felices.

A este respeito, Toffanello (2017), se manifesta falando que este procedimento deve ser usado com cautela, pois qualquer falha pode desfigurar o rosto. Então, é fundamental que os médicos e estáticos não assustem os pacientes com procedimentos mal feitos que comprometem a reputação de outros profissionais que trabalham com competência. Assim, os profissionais devem ser comprometidos com a saúde, deixando de lado a ganância e a avareza.

Segundo Faria e Santos (2019), o procedimento pode ser associado a qualquer protocolo anticelulitícos, pois através das massagens na ventosaterapia, ocorre a massagem 
linfática e redução da retenção de liquídos no organismo. Além disso, a ventosaterapia a vácuo tonifica os músculos e recupera a elasticidade. Enfim, o protocolo também é indicado para redução das estrias, motivo pelo qual as mulheres têm aderido em peso a esta prática. Com isso, a técnica tem sofrido mudanças, de acordo com o perfil do paciente.

De acordo com Pereira (2017), os protocolos para redução de estresse e ansiedade realizados na estética visam minimizar os impactos na pele, utilizando a ventosaterapia para essa finalidade. Deste modo, embora seja uma técnica bastante antiga, grandes tem sido as inovações no uso dessa técnica relacionada a metodologias dentro da estética, pois o método apresenta um potencial sensacional. Assim, é bastante explorado na terapêutica do acne para a redução da oleosidade da pele, oxigenação e ativa a circulação. Então, melhora o aspecto estético do rosto, devolvendo a autoestima aos pacientes.

Corrradi (2019), ressalta que o procedimento em si tem sido um eficiente na redução de medidas, especialmente quando esse procedimento é associado a cosmetologia que utiliza produtos nos quais seus princípios ativos redutores. Entretanto, é preciso salientar que a aspiração deve acontecer de forma leve de vácuo, pois assim ação contribuirá no aspecto da reparação e consolidação de todo tecido, permitindo uma reorganização das fibras do colágeno, diminuindo cicatrizes e estrias.

Embora seja um procedimento bastante eficiente, é necessário advertir que existem algumas contraindicações, sendo elas: hipertermias, espasmos, convulsões, ulcerações da pele, alergias Cutâneas, doenças Mentais, doenças Hemorrágicas, doenças Infeciosas Agudas, em idosos debilitados e em mulheres gestante este método não é recomendável. Mais uma vez é preciso salientar que o procedimento somente poderá ser realizado por profissional habilitado, pois dependendo de quem o realize pode o paciente sofrer lesões devido o manuseio errado.

\section{CONSIDERAÇÕES FINAIS}

Os achados literários demostraram que os tratamentos alternativos através da ventosaterapia, apresentam eficientes resultados, que não apresentam nenhum tipo de efeito colateral. Além disso a ventosaterapia também pode ser utilizada para fechamento de diagnóstico de distúrbios energéticos. Entretanto, é de extrema importância estudos 
sobre os vastos benefícios trazidos pela ventosoterapia não apenas na área da estética mais de modo geral.

É preciso salientar que para cada de procedimento é utilizado os protocolos devido, uma vez que é indicada enes tratamentos dentro da estética. Deste modo, destaca-se tratamento de estrias, cicatrizes, redução de gordura abdominal, redução de retenção de liquídos, promovendo melhoria em todo fluxo sanguíneo, melhorias no bem-estar e satisfação. Finalmenate, acredita-ase que a ventosaterapia apresentam um grande potencial na promoção da saúde e deve ser explorado na área da saúde e na estética devido seus grandes beneficios e a relação custo beneficio e resultados do procedimento.

\section{REFERÊNCIAS}

ABOUSHANAB, Tamer S.; ALSANAD, Saud. Cupping Therapy: an overview from a modern medicine perspective. Journal Of Acupuncture And Meridian Studies, [S.L.], v. II, n. 3, p. 83-87, jun. 2018. Medical Association of Pharmacopuncture Institute. http://dx.doi.org/ı.1016/j.jams.2021.06.015.

AL-BEDAH, Abdullah M.N. et al. The medical perspective of cupping therapy: effects and mechanisms of action. Journal Of Traditional And Complementary Medicine, [S.L.], v. 9, n. 2, p. 90-97, abr. 2019. Elsevier BV. http://dx.doi.org/Io.1o16/j.jtcme.2018.03.003.

BORGES, Fábio dos Santos; SCORZA, Flávia Acedo. Terapêutica em Estética: Conceitos e Técnicas. I.ed. São Paulo: Phorte, 2or6.Disponível: https://issuu.com/phorteeditora/docs/terapeutica_em_estetica. Acesso: I5 Jun.202I.

BOUSHANAB, Tamer S. e ALSANAD, Saud. Terapia de ventosa: uma visão geral de uma perspectiva da medicina moderna. J Acupunct Meridian Stud., V. II, n. 3, pág. 83-87, 2018. DOI: I0.1016 / j.jams.2018.02.001.

CARDOSO, ANA CAROLINA LIMA RAMOS. Terapia de ventosa e crônica dor nas costas: revisão sistemática e meta-análise. Rev Lat Am Enfermagem, v.26,2018.Disponível: https://doi.org/I0.1590/1518-8345.2888.3094.Acesso: II Jun.2021.

CALOGERO, R. Tipos de utilização da ventosaterapia. Embramec- Escola Brasileira de Medicina Chinesa.São Paulo, 2017. Disponível em: https://www.ebramec.edu.br/wpcontent/uploads/2019/o2/TIPOS-DE-UO-DA VENTOSATERAPIA.pdf. Acesso em: 23 Jun.2021.

COELhO, N. L.; SOUSA, J. T.; WATANABE, L. A. R.. A utilização da medicina tradicional chinesa na redução do estresse. Scire Salutis, v.9, n.I, p.20-29, 2019. DOI: http://doi.org/ro.60o8/CBPC2236- 9600.2019.001.0003. 


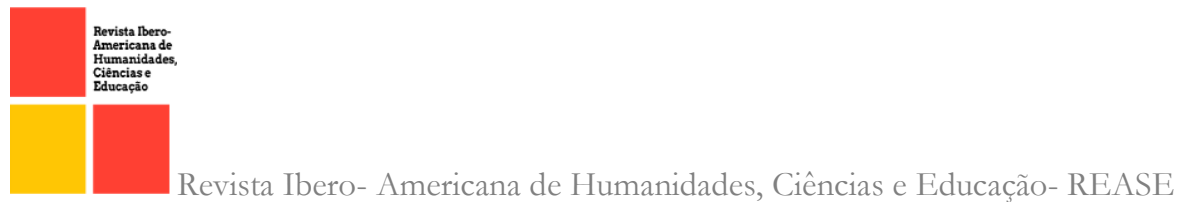

CORRADI, Analaura; PANTOJA, Alessandra F. de S.; FONSECA, Juvânia M.R.; MORAES, Yuri A. de A. Endermoterapia: Uma Revisão Bibliográfica.Id on Line Rev.Mult. Psic., 2019, vol.13, n.45, p. 655-663. ISSN: 1981- II79.Disponível: file:///C:/Users/edna/Downloads/r697-6674-I-PB\%2o(I).pdf. Acesso: 23 Jun.2021.7

FARIA GL; SANTOS JT; SANTOS DS. Efeitos da terapia manual, cinesioterapia, ventosaterapia e massoterapia no tratamento das sintomatologias da doença de Parkinson. Bahia. 2019.Disponível: http://repositorio.faema.edu.br/handle/123456789/1710. Acesso: 21 Jun.2021

FILHO, R. C. S. Ventosaterapia Chinesa - I⿳⺈ ed. - 2017.

FOSTER NE, ANEMA JR, CHERKIN D, CHOU R, COHEN SP, GROSS DP, FERREIRA PH, FRITZ JM, KOES BW, PEUL W, TURNER JA, MAHER CG; LANCET LOW BACK PAIN SERIES WORKING GROUP. Prevention and treatment of low back pain: evidence, challenges, and promising directions. Lancet. $2018 \mathrm{Jun}$ 9;391(Io137):2368-2383. doi: Io.1016/Sor40-6736(18)30489-6. Epub 2018 Mar 21. PMID: 29573872.

GONÇALVES, MAYLA FARIAS. ROSA, ALINE NANDI DA. tratamento do fibro edema gelóide no glúteo com a utilização da radiofrequencia e endermoterapia , Santa Catarina - SC, 2017. URL: http://www.riuni.unisul.br/handle/12345/2191.

GOUVEIA,L.,NUNES,G., $\quad$ PEREIRA,L.,ASSIS, I. Atuação da endermoterapia/vacuoterapia no tratamento do fibro edema gelóide - revisão de literatura. Revista Saúde em Foco - Edição no $\mathrm{n}^{\mathrm{O}}$ - Ano: 2018. Disponível: https://portal.unisepe.com.br/unifia/wpcontent/uploads/sites/rooor/2018/o7/o66_ATU

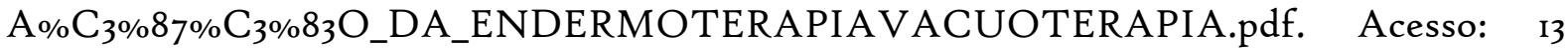
Jun.2021.

HONG, Minyoung et al. Cognitive and Emotional Aspects of Cupping Therapy. Brain Sciences, [S.L.], v. Io, n. 3, p. I44-I53, 4 mar. 2020. MDPI AG. http://dx.doi.org/ro.339o/brainsciroozor44.

HONG, Minyoung et al. Attentional Bias Toward Cupping Therapy Marks: an eyetracking study. Journal Of Pain Research, [S.L.], v. 13, n. I, p. I04I-1047, maio 2020. Informa UK Limited. http://dx.doi.org/I0.2147/jpr.s252675.

MELLO K. RONANN, A Endermoterapia aplicada ao Fibro Edema Gelóide. In: Anais da I3 $^{\text {a }}$ Mostra de Iniciação Científica 20I6 ISBN 9788563570-44-4. Disponível em: http://trabalhos.congrega.urcamp.edu.br/index.php/mic/article/view/592. Acesso: I8 Jun.2021. 
NASB, Mohammad et al. Dry Cupping, Ischemic Compression, or Their Combination for the Treatment of Trigger Points: a pilot randomized trial. The Journal Of Alternative And Complementary Medicine, [S.L.], v. 26, n. I, p. 44-50, I jan. 2020. Mary Ann Liebert Inc. http://dx.doi.org/ro.1089/acm.2019.0231

OLIVEIRA, M.A.R., SILVA, A.P., PEREIRA,L.P. Ventosaterapia uma revisão de literatura. Revista Saúde em Foco - Edição no Io - Ano: 2018.

OLIVEIRA, M. A. R. SILVA, A. P. PEREIRA,L. P. Ventosaterapia e pelling. Revista Saúde em Foco, São Lourenço, 2019. Disponível em: http://portal.unisepe.com.br/unifia/wpcontent/uploads/sites/roool/2018/o6/or7_VENT OSATERAPIA_REVIS\%C $3 \% 83{ }_{3} \mathrm{O}_{2} D E \_L I T E R A T U R A . p d f$ Acesso em: 21 Jun 2021.

PEREIRA, G.L. Tratamento de Acne por meio da acupuntura estética - revisão literária. 2017. Disponível em: https://pt.scribd.com/document/344428995/78-Tratamento-deAcne-Por-Meio-Da-Acupuntura-EstYtica-Y-RevisYo-LiterYria. Acesso em:2I Jun 202I.

PIRES, Eduardo Di Oliveira et al. Efetividade da liberação miofascial por meio da ventosaterapia na dor, limitação de movimento e capacidade funcional de portadores de lombalgia. Revista De Trabalhos Acadêmicos-Universo- GOIÂNIA, n. 5, 2018. Disponívelem:http://www.revista.universo.edu.br/index.php?journal=3GOIANIA4\&pag $\mathrm{e}=$ article\&op=view File \& path\%5B $\% 5 \mathrm{D}=$. Acesso em: is de out. 2020.

REIS, C.T e VIERA E.K. Recursos terapêuticos no tratamento de estrias.Revista Saúde Integrada (ISSN 2447-7079) V II n⿳0口䒑22 $\quad$ p. 50-70 .2018. Disponível http://local.cnecsan.edu.br/revista/index.php/saude/article/view/589.Acesso: Jun.2021.

TOFFANELLO, T. A combinação endermosucção e emulsão anfotérica para o crescimento e saúde capilar. Belevisage, São Paulo, 2017. Disponível em: http://www3.sp.senac.br/hotsites/blogs/InterfacEHS/wpcontent/uploads/2020/o6/Artg o-7.pdf. Acesso em: or jun. 202I.

VOLPATO, Maria Palharim et al. A sessão de terapia de ventosa única melhora dor, sono e incapacidade em pacientes com dor lombar crônica inespecífica. J Acupunct Meridian Stud., V. 13, no. 2, pág. 48-52, 2020. DOI: 10.1016/ j.jams.2019.11.004. 